\title{
GAMIFICATION STUDY: REVIEW AND RETRIEVAL
}

\author{
Olga Kononova ${ }^{1}$ and Dmitry Prokudin ${ }^{1,2}$ \\ ${ }^{1}$ St. Petersburg National Research University of Information Technologies, Mechanics and Optics (ITMO University) \\ 197101, St. Petersburg, Russia \\ ${ }^{2}$ St. Petersburg State University, 199034, St. Petersburg, Russia
}

\begin{abstract}
The digital transformations of the modern society often outstrip the processes of science transformation, forcing science to constantly improve both technologies and applied software. The phenomenon especially characterizes scientific studies in research areas such as the Digital Economy and the Smart City. In order to the urban environment becomes smarter, gamification technologies act as the motivational mechanisms, maintaining citizens' social activity and stimulating social growth. The purpose of the paper is an identification of development trends of gamification in the context of the sociocultural urban information space. Comparative analysis results of the publications' number, Russian scientific discourse about considered subject domains as well as its correspondence to the global trends are presented. The study has applied the synthetic method for the automated extraction and explication of contextual knowledge from an array of textual modality resources.
\end{abstract}

\section{KEYWORDS}

Context, Contextual Knowledge Explication, Full-Text and Multimodal Search, Gamification, Terminological Landscape

\section{INTRODUCTION}

In the relation to the implementation of Urban Development Projects, there is a number of main directions of interdisciplinary research areas. "Gamification in the social, scientific and educational subject domains" is one of these directions. The main topic of this direction is a gamification phenomenon which is the modern trend of technologies in social life. The purpose of the study presented in this paper is to identify the terminological landscape of gamification domain with usage of retrieval systems and semantic tools. A comparative analysis of the terminological landscape on the base of Synthetic Method presented by the authors [Kononova, Prokudin, 2018] has revealed the contexts of using gamification in the urban environment development and the modern city management. It has also highlighted promising proposals and practices on gamification using in the development of the city information space and formed the terminological base and thesaurus. Comparison of Russian with Global trends of gamification used in the development of the modern urban information environment has allowed focusing the attention of researchers on scientifically significant results. Synthetic Method proposed as an approach to the terminologically study and review has been successfully applied for the following interdisciplinary studies such as "Digital Economy: e-governance and smart technology" [Kononova, Prokudin, 2018], "Social parameters and reasons for getting involved in games" [Kononova at el., 2016], "Organization Scientific Research Activities" [Kononova, Liapin, 2016].

\section{CONTEXTUAL KNOWLEDGE EXPLICATION}

\subsection{The Review of Gamification Studies}

The terminological base forming has required the systematization of ideas in the area of study, extraction and application of contextual knowledge. The term 'gamification' was entered in business society and later in the scientific community in 2010. The use peak of this term was in 2016 and 2017. Researchers have now found 
many applications for digital gamification, linking gamification with solving social, public, cultural, and civil problems. Some of researchers believe that game mechanisms can stimulate e-participation and citizens' social behavior [Dorcec et al., 2019; Vanolo, 2018]. Although the academic debate on gamification is rather new, the scientific discourse has led to the understanding of using the possibility of gamification elements for urban development. No doubt, the global community recognizes the importance of gamification as a scientific phenomenon and conducting research in this area in order to learn how digital gamification can change our experience of the urban space using [Mueller et al., 2018]. The main directions of the modern research topics of the gamification phenomenon are presented in Table 1.

Table 1. Comparative review of gamification publications

\begin{tabular}{|c|c|}
\hline Mechanisms & Spheres \\
\hline \multicolumn{2}{|r|}{ Education, Training } \\
\hline Motivation & L. Da Rocha Seixas, et al., 2016; L. Sera, et al., 2017; R. Landers, et al., 2017 \\
\hline \multicolumn{2}{|r|}{ Business, Marketing, } \\
\hline Motivation & $\begin{array}{l}\text { A. Shpakova, et al., } 2016 \\
\text { O. El-Telbany, A. Elragal, } 2017\end{array}$ \\
\hline Communication & $\begin{array}{l}\text { A. Kampker, et al., 2014; A. Shpakova et al., 2016; L.F. Rodrigues et al., 2016; K. } \\
\text { Huotari, J. Hamari, } 2017\end{array}$ \\
\hline $\begin{array}{l}\text { Communication/ } \\
\text { Engagement }\end{array}$ & Ipeirotis, et al., 2014; Hamari, 2013, 2015; Y. Yang, et al., 2017 \\
\hline \multicolumn{2}{|r|}{ Professional Communications, e-Government } \\
\hline Motivation & J.T. Harviainen, et al., 2019; T. Dargan, F. Evequoz, 2015 \\
\hline Engagement & M. Romano, et al., 2016; Agbozo E., Chepurov E. (2018); Hassan L., Hamari J. (2019) \\
\hline \multicolumn{2}{|r|}{ Health and Sport, Culture and Tourism } \\
\hline Motivation & Jones, et al., 2014; J. Hamari, J. Koivisto,2015 \\
\hline $\begin{array}{l}\text { Communication/ } \\
\text { Engagement }\end{array}$ & F. Xu, et al., 2017 \\
\hline $\begin{array}{l}\text { Motivation/ } \\
\text { Communication }\end{array}$ & N. P. Cechetti et al., 2019 \\
\hline \multicolumn{2}{|r|}{ Urban Planning and Development, Civic Participation } \\
\hline Motivation & T. AlSkaif, et al., 2018 \\
\hline Engagement & $\begin{array}{l}\text { T. AlSkaif, et al., 2018; R. Olszewski et al., 2017; M. R. Zica, et al., 2017; A. Vanolo, } \\
\text { 2018; D. Johnson, et al., 2017; M. Romano et al., } 2016\end{array}$ \\
\hline \multicolumn{2}{|r|}{ Ecology } \\
\hline Motivation & S. Castellanos, 2016; T. AlSkaif, et al., 2018; D. Wemyss et al., 2019 \\
\hline
\end{tabular}

Analysis of scientific publications has shown that gamification is used in the practice of managing urban areas: Transport, Utilities, Energy Saving, Waste Recycling, Ecology, and Urban Environment Preservation. Moreover, it is used in planning urban information spaces, implementing intelligent urban projects and producing "digital citizens". Gamification methods are also used in Education, Health, Culture, Tourism, e-Government, Civic e-Participation, Urban Cartography and Logistics, City Data Collection (IoT), and others. Both the media space and scientific literature have reflected this phenomenon.

Regardless of the application sphere, even when it comes to business, the authors of all publications write about gamification. They approach this issue first of all, as an instrument of motivation and self-organization, secondly, as support for social and professional communications, and, thirdly, as human-machine interactions (engagement, e-participation, e-involvement). It should be noted that selected spheres' combination presents modern city in all its diversity; selected gamification mechanisms (communication, motivation, engagement) correspond to Conceptualization of gamification [Huotari \& Hamari, 2017] with its sequential addiction of affordances, psychological outcomes, behavioral outcomes.

\subsection{Gamification in Russian and English Discourse}

The theoretical basis of the study is discourse analysis, advanced content analysis with the subsequent explication of selected contexts (synthetic method), expert, and comparative analysis. The authors' automated technique of extraction and explication of contextual knowledge (a form of an interpretation of the texts and explication of meanings through contexts obtained as a result of search queries), using a hybrid 
query for the analysis of contexts from textual modality information resources, has been applied [Kononova, Prokudin, 2018].

In order to evaluate the dynamics of research interest to Gamification Technology, the study proposes a review of the corpus of Russian and Foreign scientific publications, as well as Russian media publications. Because of the synthetic method is independent of the instrumental environment for conducting research, the presentation language and the text format, the technique validation was performed for arrays of Russian and English scientific publications. The Russian web-based information systems libraries eLibrary (https://elibrary.ru/), T-Libra (http://77.234.221.107/bin/TauC.exe?DSN=tlibra), and multilingual web-based tool Voyant-Tools (https://voyant-tools.org/) has been used as the tools for search, explication, and analysis of contexts.

At this stage of the research, two corpuses of texts from Russian and English sources were searched and formed. The search has been carried out since 2010 and generally confirmed the findings of researchers who claimed that scientific papers on gamification appeared in the scientific discourse and in open sources in 2010. The results of the analysis of both textual corpuses in the given interval have shown the growing interest in the gamification. The first corpus contains the information resources from ScienceDirect, Web of Science и Scopus. There were 301 scientific publications found for the thematic query "gamification", selected in an expert manner on the relevance basis of the study subject domain. The dynamics of the scientific community interest (in the number of publications by year) to the topic of gamification demonstrates the following growth: $2011-5 ; 2012-11 ; 2013-20 ; 2014-25 ; 2015-45 ; 2016-47$; $2017-61 ; 2018-56$. Analysis of English text corpus has also allowed grouping the term-concepts corresponding with 'gamification' search queries. Firstly, 55 publications were selected from English text corpus for the period of 2015-2018. Then 18 papers relevant to topics of gamification in the city were selected from them by an expert method. The list of these term-concepts can become a part of the terminological core of subject domain in the future.

The results of the data analysis (Figure 1) have led to the following conclusions: the number of scientific publications on gamification in the world has been growing annually since 2010; the growth in the number of Russian scientific publications on this topic demonstrates two year delay. However, in general, the dynamics corresponds to global scientific trends; accessibility of Russian scientific publications for researchers is about a third of all Russian scientific publications; comparison of the data from Russian scientific publications and publications from Russian media allows concluding that the topic of gamification in the public discourse is illuminated to a lesser extent.

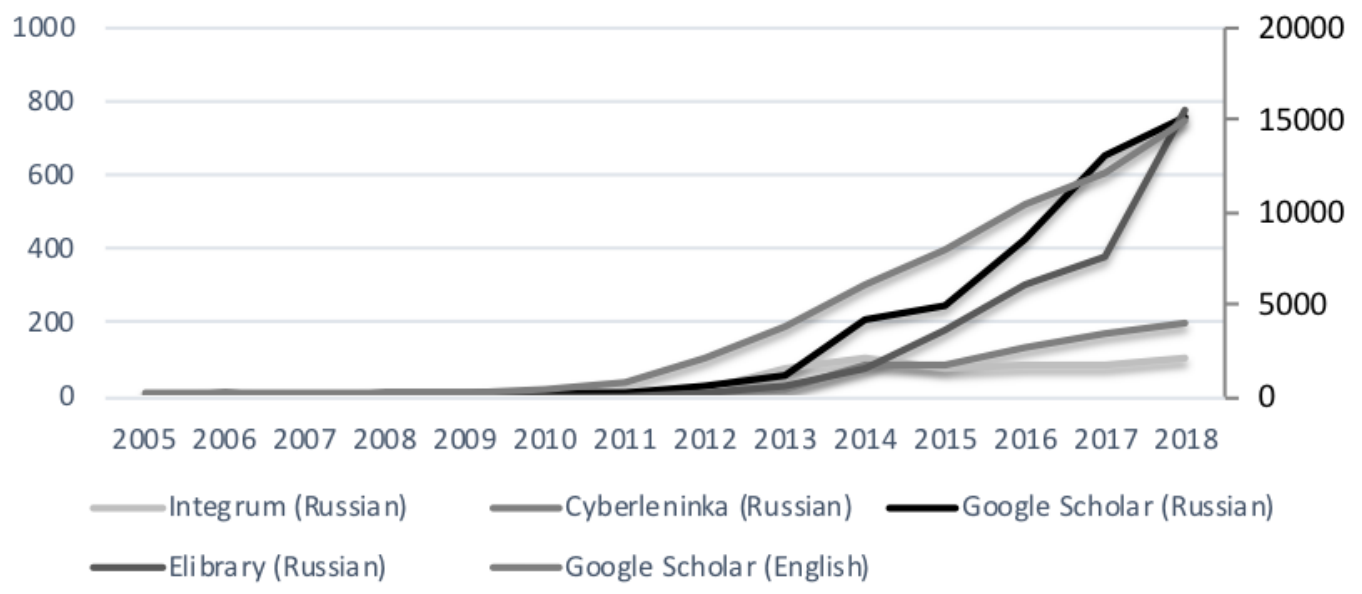

Figure 1. Dynamics of publication activity on the gamification for 2005-2018

Analysis of Russian text corpus has allowed gathering key words used from 2011 to 2018. There are some most common term-concepts: motivation, eLearning, education, game, game technology, gaming, personnel management, and others. Extra analysis of these terms' application will fill the terminological core of subject domain. 


\section{CONCLUSION}

The study has formed the following conclusions: gamification as a direction of scientific research has begun to develop in the Russian scientific discourse since 2012. It indicates the influence of global trends in scientific research in the gamification domain in Russian studies. In Russian information space gamification forms more the scientific discourse than the extended public one. The main scopes of gamification in the Russian and global scale have been determined. Both Russian and Foreign researchers pay a lot of attention of gamification technologies in education. Russian scientific discourse discusses little the use of gamification in Urban Planning and e-Participation. In addition, the basic terms-concepts of the terminological core of the interdisciplinary research direction have been defined. Further development of the research will be focused on forming a thesaurus of the interdisciplinary research direction with Synthetic Method application and structured description of thematic contexts of textual modality (text corpus, document, document fragment - several paragraphs, paragraph) with the Dublin Core Metadata Element Set. The contextual knowledge description based on Dublin Core provides the usage of thesaurus for automated search and identification of contextual knowledge by search engines, open access to knowledge, the ability to use software that, along with the Dublin Core standard, is able to exchange automatically via the OAI-PMH protocol (for instance, DSpace, https://duraspace.org/dspace/), Eprints (https://www.eprints.org/uk/), OJS (https://pkp.sfu.ca/ojs/)).

\section{ACKNOWLEDGEMENT}

The reported study was funded by RFBR according to the research project "The integrated approach elaboration to the analysis of the terminological base of the developing interdisciplinary research in distributed network environment" № 18-011-00923, 2018-2020.

\section{REFERENCES}

Agbozo E., Chepurov E. (2018) Enhancing e-Participation via gamification of e-Government platforms: A possible solution to SubSaharan African e-Government initiatives // CEUR Workshop Proceedings. Vol. 2145. P. 83-86. http://ceur-ws.org/Vol-2145/p14.pdf

AlSkaif T., Lampropoulos I., Broek M. van den, Sark W.van (2018) Gamification-based framework for engagement of residential customers in energy applications // Energy Research \& Social Science. Vol. 44. P. 187-195. DOI: 10.1016/j.erss.2018.04.043.

Barratt P. (2017) Healthy competition: A qualitative study investigating persuasive technologies and the gamification of cycling // Health \& Place. Vol. 46. P. 328-336. DOI: 10.1016/j.healthplace.2016.09.009

Castellanos S. (2016) Delivering modal-shift incentives by using gamification and smartphones: A field study example in Bogota, Colombia // Case studies on transport policy. Vol. 4. №. 4. P. 269-278. DOI: 10.1016/j.cstp.2016.08.008

Cechetti N.P., Bellei E.A., Biduski D., Rodriguez J.P. (2019) Developing and im-plementing a gamification method to improve user engagement: A case study with an m-Health application for hypertension monitoring // Telematics and Informatics. Vol. 41. P. 126-138. DOI: 10.1016/j.tele.2019.04.007

Dargan T., Evequoz F. (2015) Designing engaging e-Government services by com-bining user-centered design and gamification: A use-case // Proceedings of the 15th European Conference on eGovernment ECEG 2015 University of Portsmouth, 70.

Da Rocha Seixas L., Sandro Gomes A., de Melo Filho I. (2016) Effectiveness of Gamification in the Engagement of Students // Computers in Human Behavior. Vol. 58. P. 48-63. DOI: 10.1016/j.chb.2015.11.021

Dias L.P.S., Barbosa J.L.V., Vianna H.D. (2018) Gamification and serious games in depression care: A systematic mapping study. // Telematics and Informatics. Vol. 35. P. 213-224. DOI: 10.1016/j.tele.2017.11.002

Dorcec L., Pevec D., Vdovic H., Babic J., Podobnik V. (2019) How do people value electric vehicle charging service? A gamified survey approach // Journal of Cleaner Production. Vol. 210. P. 887-897. DOI: $10.1016 /$ j.jclepro.2018.11.032

El-Telbany O., Elragal A. (2017) Gamification of enterprise systems: A lifecycle approach // Procedia Computer Science. Vol. 121. P. 106-114. DOI: 10.1016/j.procs.2017.11.015 
Hamari J., Koivisto J., Sarsa H. (2014) Does Gamification Work? - A Literature Review of Empirical Studies on Gamification // Proceedings of the 2014 47th Hawaii International Conference on System Sciences (HICSS '14). IEEE Computer Society, Washington, DC, USA. P. 3025-3034. DOI: 10.1109/HICSS.2014.377

Harviainen J. T., Hassan L. (2019) Governmental Service Gamification: Central Principles // International Journal of Innovation in the Digital Economy (IJIDE). Vol. 10. № 3. P. 1-12. DOI: 10.4018/IJIDE.2019070101

Hassan L., Hamari J. (2019) Gamification of E-Participation: A Literature Review // Proceedings of 52nd Hawaii International Conference on System Sciences (HICSS'52), At Maui HI, USA. P. 3077-3086.

Koivistoa J., Hamari J. (2019) The rise of motivational information systems: A review of gamification research // International Journal of Information Management 45. P. 191-210. https://doi.org/10.1016/j.ijinfomgt.2018.10.013

Johnson D., Horton E., Mulcahy R., Foth V. (2017) Gamification and serious games within the domain of domestic energy consumption: A systematic review // Renewable and Sustainable Energy Reviews. Vol. 73. P. $249-264$. DOI: 10.1016/j.rser.2017.01.134

Jones B.A., Madden G.J., Wengreen H.J. (2014) The FIT Game: preliminary evalua-tion of a gamification approach to increasing fruit and vegetable consumption in school // Prev Med. Vol. 68. P. 76-79. DOI: 10.1016/j.ypmed.2014.04.015

Kononova O., Prokudin D. (2018) Synthetic Method in Interdisciplinary Termino-logical Landscape Research of Digital Economy // SHS Web Conf. Vol. 507. 01082. DOI: 10.1051/shsconf/20185001082

Kononova, O., Liapin S. (2016) Using the Contextual Search for the Organization Scientific Research Activities. Communications in Computer and Information Science. Vol. 674. P. 392-399. DOI: 10.1007/978-3-319-49700-6_38

Kononova, O., Sergeeva O., Orekh E., Kudriavtceva M. (2016) Towards Computer Game Research Area in Russia. Communications in Computer and Information Science. Vol. 674. P. 72-81. DOI: 10.1007/978-3-319-49700-6_9

Konstantakopoulos I.C., Barkan A.R., He S., Veeravalli T., Liu H., Spanos C. (2019) A deep learning and gamification approach to improving human-building in-teraction and energy efficiency in smart infrastructure // Applied Energy. Vol. 237. P. 810-821. DOI: 10.1016/j.apenergy.2018.12.065

Landers R., Bauer K., Callan R. (2017) Gamification of task performance with lead-erboards: A goal setting experiment // Computers in Human Behavior. Vol. 71. P. 508-515. DOI: 10.1016/j.chb.2015.08.008

Marcucci E., Gatta V., Le Pira V. (2018) Gamification design to foster stakeholder engagement and behavior change: An application to urban freight transport // Transportation Research Part A: Policy and Practice. Vol. 118. P. 119-132. DOI: 10.1016/j.tra.2018.08.028

Mueller C., Klein U., Hof A. (2018) An easy-to-use spatial simulation for urban planning in smaller municipalities // Computers, Environment and Urban Systems. Vol. 71. P. 109-119. DOI: 10.1016/j.compenvurbsys.2018.05.002

Olszewski R., Gnat M., Trojanowska H., Turek A., Wieladek A. (2017) Towards Social Fuzzy Geoparticipation Stimulated by Gamification and Augmented Reality // 13th International Conference on Natural Computation, Fuzzy Systems and Knowledge Discovery (ICNC-FSKD 2017). P. 1363-1370. DOI: 10.1109/FSKD.2017.8392965

Richter G., Raban D.R., Rafaeli S. (2015) Studying Gamification: The Effect of Re-wards and Incentives on Motivation // Gamification in Education and Business. Springer, Cham. P. 21-46. DOI 10.1007/978-3-319-10208-5_2

Rodrigues L.F., Carlos A.O., Costa J. (2016) Does ease-of-use contributes to the per-ception of enjoyment? A case of gamification in e-banking // Computers in Human Behavior. Vol. 61. P. 114-126. DOI:10.1016/j.chb.2016.03.015

Romano M., Onorati T., Aedo I., Diaz P. (2016) Designing mobile applications for emergency response: citizens acting as human sensors // Sensors. Vol. 16. № 3. 406. DOI: 10.3390/s16030406

Sera L, Wheeler E. (2017) Game on: The gamification of the pharmacy classroom // Curr Pharm Teach Learn. Vol. 9. №. 1. P. 155-159. DOI: 10.1016/j.cptl.2016.08.046

Shpakova A., Dörfler V., Macbryde J. (2016) The role (s) of gamification in knowledge management // EURAM 2016: 16th Annual Conference of the European Academy of Management. P. 1-40. https://strathprints.strath.ac.uk/56368/

Sardi L., Idri A., Fernandez-Aleman J.L. (2017) A systematic review of gamification in e-Health // Journal of Biomedical Informatics. Vol. 71. P. 31-48. DOI: 10.1016/j.jbi.2017.05.011

Vanolo A. (2018) Cities and the politics of Gamification // Cities. Vol. 74. P. 20-326. DOI: 10.1016/j.cities.2017.12.021

Wellington R. (2015) Context to Culture for Gamification // HCI Requirements: Familiarity and Enculturement. Gamification in Education and Business. Springer, Cham. P. 151-165. DOI 10.1007/978-3-319-10208-5_8

Wemyss D., Cellina F., Lobsiger-Kagi E., de Luca V., Castri R. (2019) Does it last? Long-term impacts of an appbased behavior change intervention on household electricity savings in Switzerland // Energy Research \& Social Science. Vol. 47. P. 16-27. DOI: 10.1016/j.erss.2018.08.018

Xu F., Buhalis D., Weber J. (2017) Serious games and the gamification of tourism // Tourism Management. Vol. 60. P. 244-256. DOI: 10.1016/j.tourman.2016.11.020 330

Yen B.T.H., Mulley C., Burke M. (2019) Gamification in transport interventions: Another way to improve travel behavioural change // Cities. Vol. 85. P. 140-149. DOI: 10.1016/j.cities.2018.09.002 